\title{
Rapamycin enhances the sensitivity of ER-positive breast cancer cells to tamoxifen by upregulating p73 expression
}

\author{
LEI ZHU ${ }^{1 *}$, XIAO-XIA LI ${ }^{2 *}$, LIANG SHI $^{1}$, JING WU $^{2}$, JIA-YI QIAN $^{1}$, TIAN-SONG XIA ${ }^{1}$, \\ WEN-BIN ZHOU ${ }^{1}$, XI SUN ${ }^{1}$, XU-JIE ZHOU ${ }^{2}$, JI-FU WEI ${ }^{3}$ and QIANG DING ${ }^{1}$ \\ ${ }^{1}$ Jiangsu Breast Disease Center, The First Affiliated Hospital with Nanjing Medical University; \\ ${ }^{2}$ Department of Critical Care Medicine, The First Affiliated Hospital with Nanjing Medical University; \\ ${ }^{3}$ Research Division of Clinical Pharmacology, The First Affiliated Hospital with Nanjing Medical University, \\ Nanjing, Jiangsu 210029, P.R. China
}

Received March 21, 2018; Accepted October 16, 2018

DOI: $10.3892 /$ or.2018.6842

\begin{abstract}
A total of $70 \%$ of breast cancers express the estrogen receptor (ER) $\alpha$; therefore, targeting the ER may be an effective endocrine therapy with which to inhibit breast cancer growth. Tamoxifen is the most common-used clinically used drug for the treatment of advanced or metastatic ER-positive $\left(\mathrm{ER}^{+}\right)$breast cancer. However, a substantial proportion of patients become resistant to endocrine therapies. To overcome this limitation, in this stud, we sought to maximize the benefits associated with tamoxifen therapy via drug combination strategies. We demonstrated that rapamycin, an FDA-approved mammalian target of rapamycin (mTOR) inhibitor, enhanced the effects of endocrine therapy with tamoxifen, and the concentration of tamoxifen required for $\mathrm{ER}^{+}$breast cancer cell growth inhibition was substantially reduced. Moreover, treatment with rapamycin plus tamoxifen significantly inhibited tumor growth in vivo. In addition, this synergistic effect may be mediated by the induction of p73. We revealed a novel mechanism in which $\mathrm{p} 73$ increases ER $\alpha$ expression by directly binding to the promoter region of the ER $\alpha$ gene. Taken together, the findings of this study indicate that combination therapy with rapamycin and tamoxifen underlying p73-mediated ER $\alpha$ expression may provide new insight into the drug combination for the treatment of $\mathrm{ER}^{+}$breast cancer.
\end{abstract}

Correspondence to: Dr Qiang Ding, Jiangsu Breast Disease Center, The First Affiliated Hospital with Nanjing Medical University, 300 Guangzhou Road, Nanjing, Jiangsu 210029, P.R. China

E-mail: dingqiang@njmu.edu.cn

Dr Ji-Fu Wei, Research Division of Clinical Pharmacology, The First Affiliated Hospital with Nanjing Medical University, 300 Guangzhou Road, Nanjing, Jiangsu 210029, P.R. China

E-mail:weijifu@hotmail.com

*Contributed equally

Key words: breast cancer, rapamycin, tamoxifen, p73, estrogen receptor $\alpha$, synergism

\section{Introduction}

Breast cancer is a complex disease and the major cause of cancer-related mortality among women. Approximately $70 \%$ of breast cancers express the estrogen receptor (ER) and are thus termed ER-positive $\left(\mathrm{ER}^{+}\right)$breast cancers, which represent the primary luminal molecular subtype of breast cancer (1-3). Generally, patients with $\mathrm{ER}^{+}$breast cancer have a better efficacy and prognosis than those with ER-negative (ER ${ }^{-}$) breast cancer (4). ER can be categorized into two structurally related genes, $\mathrm{ER} \alpha$ and $\mathrm{ER} \beta$, in which $\mathrm{ER} \alpha$ is a major regulator of breast cancer development and progression $(5,6)$. Therefore, therapies targeting ER, known as endocrine therapies, have become the mainstay of prevention and treatment of all stages of $\mathrm{ER}^{+}$breast cancers $(7,8)$. The common drugs used in endocrine therapy in breast cancer include the following: i) Selective ER modulators (SERM), such as tamoxifen, which directly inhibit ERs by selecting estrogen modulators with mixed agonistic/antagonistic activities; ii) selective ER downregulators (SERD), such as fulvestrant, which inhibit ER signaling through the degradation of ER expression; iii) aromatase inhibitors, such as letrozole, which deprive the receptor's ligand by blocking estrogen production $(9,10)$.

Tamoxifen, the first-line endocrine drug used in the treatment of $\mathrm{ER}^{+}$breast cancer, has contributed to a marked increase in the long-term survival rate $(11,12)$. Nevertheless, a considerable proportion of patients with localized breast cancers and metastatic breast cancers become resistant to endocrine therapies (13). In view of this, high-dose tamoxifen ( $>100 \mathrm{mg}$ daily) is used in place of standard-dose tamoxifen (20 $\mathrm{mg}$ daily) for the treatment of the above-mentioned breast cancers (14). However, this treatment is associated with severe side-effects, including hyperplasia, venous thromboembolic disease (15) and acquired tamoxifen resistance $(16,17)$.

To overcome this limitation, novel strategies to reduce the dose of tamoxifen, while still maintaining its anticancer functions are currently under investigation (18). Some clinically used drugs, which were not developed for the treatment of cancer previously, may have some antitumor effects which may enhance the sensitivity of $\mathrm{ER}^{+}$tumors to tamoxifen. For example, the anti-diabetic drug, metformin, has been shown to 
enhance the tamoxifen-mediated tumor growth inhibition of $\mathrm{ER}^{+}$breast cancer (19). The selective cyclooxygenase (COX)-2 inhibitor, celecoxib, has also been shown to alleviate the tamoxifen-induced angiogenic effects in metastatic $\mathrm{ER}^{+}$breast cancer (20). Recently, it has been reported that the activation of mammalian target of rapamycin (mTOR) signaling leads to multiple agent therapeutic resistance in $\mathrm{ER}^{+}$breast cancer (21). Rapamycin, an mTOR inhibitor, which is a macrolide immunosuppressant and was originally used for the prevention of organ transplant rejection and approved by the US Food and Drug Administration (FDA) in September, 1999 for its safety, has been found to synergize with cisplatin in the treatment for basal-like breast cancer cell (22). Moreover, a phase II neoadjuvant endocrine therapy clinical trial demonstrated the synergistic effects of the combination of the mTORC1 inhibitor, everolimus, with letrozole in the treatment of breast cancer (23). However, to the best of our knowledge, there were few studies to date which have investigated whether rapamycin has the potential to enhance the sensitivity of $\mathrm{ER}^{+}$breast cancers to tamoxifen.

In the present study, we found that rapamycin indeed enhanced the sensitivity of $\mathrm{ER}^{+}$breast cancer cells to tamoxifen both in vitro and in vivo. Moreover, we found that this synergistic effect may be mediated partly through the upregulation of ER expression following the induction of p73. Taken together, combination therapy with rapamycin and tamoxifen may provide new insight and may aid in the development of novel therapeutic strategies for the treatment of $\mathrm{ER}^{+}$breast cancer.

\section{Materials and methods}

Cell culture and treatment. The human breast cancer cell lines, MCF-7 and ZR-75-1, were obtained from the American Type Culture Collection (ATCC; Manassas, VA, USA). The cells were cultured in complete medium consisting of high glucose Dulbecco's modified Eagle's medium (DMEM; Wisent Biotechnology, Nanjing, China) supplemented with $10 \%$ fetal bovine serum (FBS), $100 \mu \mathrm{g} / \mathrm{ml}$ penicillin-streptomycin (HyClone, Logan, UT, USA) at $37^{\circ} \mathrm{C}$ in a humidified atmosphere containing $5 \% \mathrm{CO}_{2}$.

For drug treatment, the MCF-7 and ZR-75-1 cells were first treated with tamoxifen (0-25 $\mu \mathrm{M}$; Sigma-Aldrich, Dorset, UK) or rapamycin (0-6 $\mu \mathrm{M}$; Sigma-Aldrich) individually for $48 \mathrm{~h}$. Following rapamycin treatment, we found the effective concentration of rapamycin started began from $40 \mathrm{nM}$ with an $\sim 20 \%$ inhibitory rate. We selected $40 \mathrm{nM}$ rapamycin to further investigate the effects of the combination of the two drugs on breast cancer. The changes in p73 and ER $\alpha$ expression following rapamycin treatment are shown in Fig. 1A and B.

Cell viability assay. Cell viability was measured using CCK-8 kits (Dojindo, Kumamoto, Japan) following the manufacturer's instruction. Briefly, the MCF7 and ZR-75-1 cells grown in monolayers were harvested and dispensed in 96-well culture plates in $200 \mu \mathrm{l}$ of DMEM at a concentration of $5 \times 10^{3}$ cells per well. After $12 \mathrm{~h}$, the differential drug concentrations of tamoxifen (0-24 $\mu \mathrm{M})$, rapamycin $40 \mathrm{nM}$, or both $0-24 \mu \mathrm{M}$ tamoxifen plus $40 \mathrm{nM}$ rapamycin were added to the cells. After $48 \mathrm{~h}$, the medium in each well was replaced with $100 \mu \mathrm{l}$
DMEM containing $10 \%$ CCK-8 to measure the growth rate of cells. The plates were incubated at $37^{\circ} \mathrm{C}$ for $2.5 \mathrm{~h}$ and the optical density (OD) values at $450 \mathrm{~nm}$ were measured using a microplate reader (Tecan Austria GmbH, Grödig, Austria). Each test was performed in triplicate.

Apoptosis assays. Apoptosis measurements were conducted using the Annexin V apoptosis detection kit (BD Biosciences, Heidelberg, Germany) according to the manufacturer's instructions. Early and late apoptotic, as well as viable cell populations were identified by plotting phycoerythrin (PE), Annexin V vs. 7-AAD (7-amino-actinamycin D). For each measurement, 3 independent samples were pooled.

Drug combination analysis. The combination analysis was conducted using the method previously described by Chou and Talalay (24). Cell viability was measured by CCK-8 assay. Drug dose-effect calculations and the combination indices (CI) for 50\% growth inhibition were obtained using GraphPad Prism 7.0 software (GraphPad, La Jolla, CA, USA), and the Student's t test was applied to verify whether the CI values at $50 \%$ growth inhibition were significantly different from $\mathrm{CI}=1$. As regards the $\mathrm{CI}$ combination indices, $\mathrm{CI}<1$ indicates synergism, $\mathrm{CI}=1$ indicates addivity, and $\mathrm{CI}>1$ indicates antagonism.

Animal model in vivo. Nude mice were used in this study, 30 female nude mice, aged 4 weeks and weighing 12-15 g, were purchased from the Animal Core Facility of Nanjing Medical University (Nanjing, China). The study was approved by the Institutional Animal Care and Use Committee for Animal Use (the Animal Ethics Committee of Nanjing Medical University). The mice were kept under the following conditions: Relative humidity, 40-70\%; room temperature, $20-26^{\circ} \mathrm{C}$; food and water, $5 \mathrm{~g}$ food and $100 \mathrm{ml}$ water per $100 \mathrm{~g}$ body weight per day. Estrogen (E2; $0.9 \mathrm{mg} / \mathrm{kg}$ ) was injected into the abdomen of the 4 -week-old female nude mice every 3 days. Subsequently, 5x10 2 ZR-75-1 cells were injected into the abdominal mammary fat pad of the mice. When the tumor volume reached $\sim 200 \mathrm{~mm}^{3}$, the mice were randomly divided into 4 groups as follows: i) The control group, in which the mice received phosphate-bufferred saline (PBS); ii) the rapamycin group, in which the mice received rapamycin $(0.25 \mathrm{mg} / \mathrm{kg}$ body weight, p.o.); iii) the tamoxifen group, in which mice received tamoxifen (60 mg/kg body weight, p.o.); and iv) the combination group, in which mice received a combination of the two drugs in their drinking water. Tumor growth was measured using a caliper each week. After 4 weeks, the mice were sacrificed and the tumors removed. The excised tumor portions were fixed in $4 \%$ paraformaldehyde for further analysis.

Immunohistochemical (IHC) staining and analysis. Breast tissue samples $(n=82)$ were obtained from the First Affiliated Hospital of Nanjing Medical University, China, between 2004 and 2007. The collection and use of the samples was reviewed and approved by the Institutional Ethics Committee of the First Affiliated Hospital of Nanjing Medical University and informed consent was obtained from all patients prior to sample collection. The TNM staging was defined according to the American Joint Committee on Cancer 
A
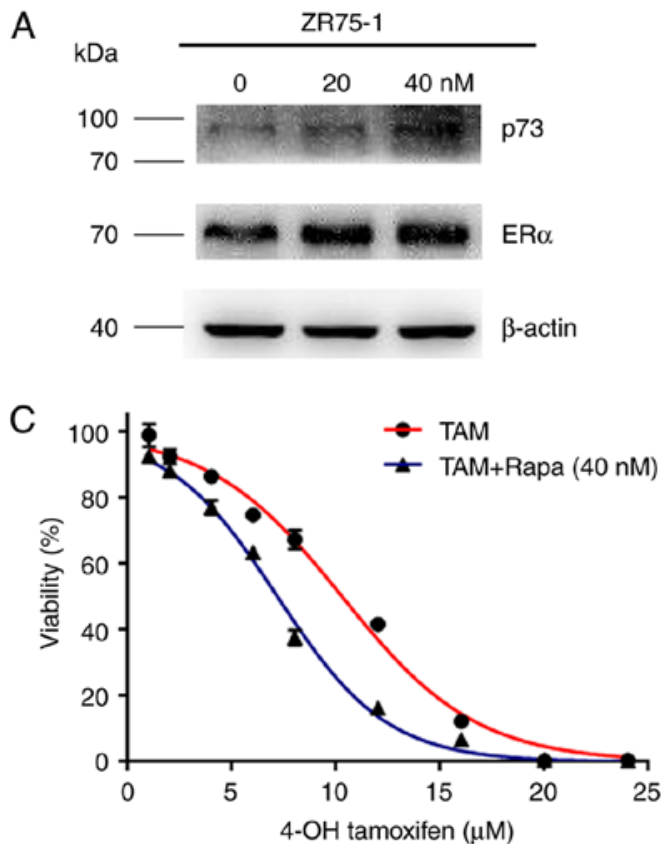

E

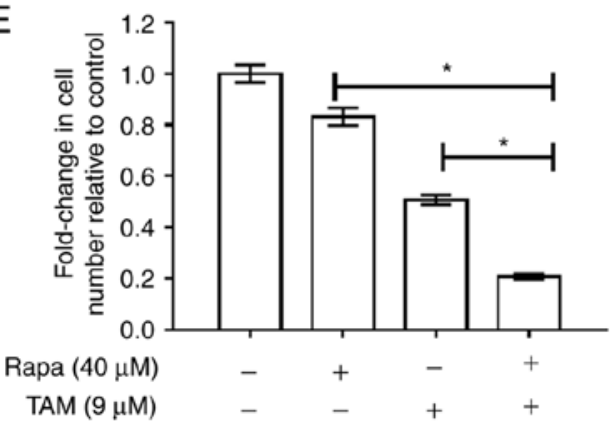

B
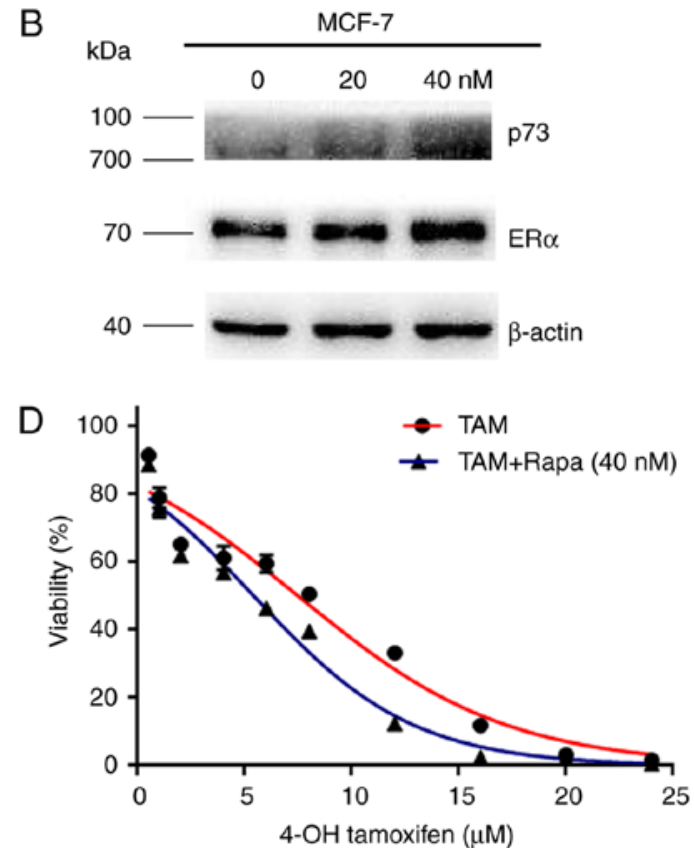

$\mathrm{F}$

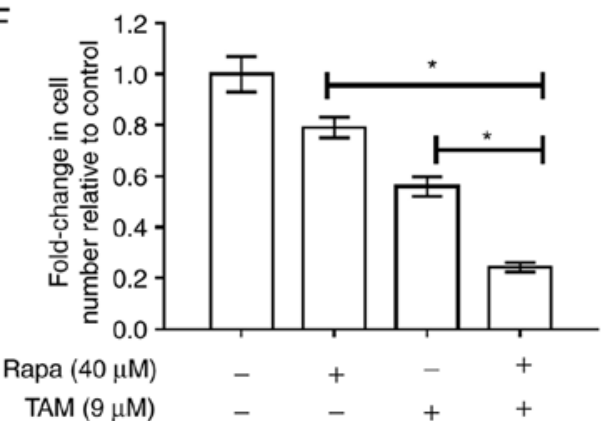

Figure 1. Rapamycin functions synergistically with tamoxifen in the MCF-7 and ZR-75-1 cells. (A and B) Changes in p73 and ER $\alpha$ expression following rapamycin treatment $(\mathrm{C}$ and $\mathrm{D}) \mathrm{MCF}-7$ and $\mathrm{ZR}-75-1$ cells were treated with tamoxifen at various concentrations $(0,1,2,4,6,8,16,20$ and $24 \mu \mathrm{M})$, or a combination of tamoxifen and rapamycin $(40 \mathrm{nM})$. After $48 \mathrm{~h}$, cell viability was measured by CCK-8 assays. (E and F) MCF-7 and ZR-75-1 cells were treated with $9 \mu \mathrm{M}$ tamoxifen, $40 \mathrm{nM}$ rapamycin, or a combination of the two agents for $48 \mathrm{~h}$, and cell viability was measured. Histograms represent the quantification of cell viability. These data were calculated from 3 separate experiments and presented as the means $\pm \mathrm{SEM}$, ${ }^{*} \mathrm{P}<0.05$ for the TAM ( $\left.9 \mu \mathrm{M}\right)$ group vs. the TAM $(9 \mu \mathrm{M})+$ Rapa (40 nM) group. TAM, tamoxifen; Rapa, rapamycin.

(AJCC) (6th version, 2002). IHC staining of the same tissue samples with p73 (diluted 1:50; cat. no. PA5-35368; Thermo Fisher Scientific, Waltham, MA, USA) and ER $\alpha$ antibodies (diluted 1:1,00; cat. no. 13258; Cell Signaling Technology, Danvers, MA, USA) was conducted and analyzed as previously described (25).

Plasmids and siRNA transfection. Plasmids and siRNA constructs of p73 siRNA targeting p73 (siRNA1, siRNA2) and a negative control (CTRi), plasmid targeting p73 and the control (Vector) were obtained from GenePharma (Shanghai, China). Briefly, the MCF-7 and ZR-75-1 cells were transfected with the plasmid or siRNAs using Lipofectamine 3000 (Invitrogen/Thermo Fisher Scientific) according to the manufacturer's instructions. The cells were cultured in a 6-well plate for 24 to $48 \mathrm{~h}$ and the expression level was detected by western blot analysis and reverse transcription-quantitative PCR (RT-qPCR) to determine the transfection efficiency.

Western blot analysis. Western blot analysis was carried out as previously described (26). The radioimmunoprecipitation assay (RIPA) kit (Beyotime Institute of Biotechnology, Shanghai, China) was used to extract protein from the breast cancer cells according to the manufacturer's instructions. The icinchoninic Acid Protein Assay kit (BCA) was used to determine the protein concentration. A total of $20 \mu \mathrm{g}$ of proteins with different molecular weights were separated on $10 \%$ SDS-PAGE gels, and transferred onto polyvinylidene fluoride (PVDF) membranes (EMD Millipore, Bedford, MA, USA) in transfer buffer. The membranes were then blocked in $5 \%$ non-fat milk at room temperature for $\sim 2 \mathrm{~h}$ and incubated in the specific primary antibodies at $4^{\circ} \mathrm{C}$ overnight. After washing in TBST, the membranes were incubated with secondary antibodies at room temperature for $\sim 2 \mathrm{~h}$. ECL Plus (EMD Millipore) was used to detect the protein bands with the Bio-Imaging System. The following detection antibodies were used: p73 (diluted 1:1,000; cat. no. 14620), $\mathrm{ER} \alpha$ (diluted 1:1,000; cat. no. 13258), anti-rabbit secondary antibodies (diluted 1:1,000; cat. no. 7074), anti-mouse secondary antibodies (diluted 1:1,000; cat. no. 7076) (all from Cell Signaling Technology) and $\beta$-actin (diluted 1:1,000; cat. no. AA128; Beyotime). 
$R N A$ extraction and $R T-q P C R$. Total RNA was extracted using TRIzol reagent (Takara, Kusatsu, Japan). Reverse transcription and qPCR were performed as previously described (27). The following PCR primers were used to amplify the relevant genes: $\beta$-actin forward, $5^{\prime}$-GCTGTGCTATCCCTGTACGC-3' and reverse, 5'-TGCCTCAGCGCAGCGGAACC-3'; p73 forward, 5'-CGGGCCATGCCTGTTTACA-3' and reverse, 5'-TGTCCTTCGTTGAAGTCCCTC-3'; ER $\alpha$ forward, 5'-CCC ACTCAACAGCGTGTCTC-3' and reverse, 5'-CGTCGATTA TCTGAATTTGGCCT-3'. the method of quantification was $2^{-\Delta \Delta C \mathrm{t}}(28)$.

Dual-luciferase reporter assay. Dual-luciferase reporter assays were conducted in triplicate using respective kits (Promega, Madison, WI, USA) according to the manufacturer's instructions. Briefly, $200 \mathrm{ng}$ of a pGL3 reporter containing target regions, an internal control, and $5 \mathrm{ng}$ of Renilla luciferase vector (pRL-TK; Promega) were co-transfected into the breast cancer cells. After $48 \mathrm{~h}$, the cells were harvested to measure the luciferase activity. All the experiments were conducted at least 3 times.

Chromatin immunoprecipitation (ChIP). ChIP assays were performed using chromatin immunoprecipitation kits (17-371, EZ-ChIP; EMD Millipore, Billerica, MA, USA) according to the manufacturer's instructions as described previously (29). The primary antibody used was anti-rabbit p73. An aliquot $(2 \mu \mathrm{l})$ of each sample was analyzed by PCR using specific primers listed as follows: Sense, 5'-GCACTTAGAAATGGTCCTGGTAA-3' and antisense, 5'-CCTGCTCAATGACAATCACACT-3'.

Statistical analysis. Each experiment in this study was repeated in triplicate, unless otherwise specified. The data were analyzed using SPSS software (version, 22.0). The association between $\mathrm{p} 73$ and the patient clinicopathological parameters was analyzed using $\chi^{2}$ tests. The correlation between the expression levels of p73 and ER $\alpha$ in the breast cancer specimens was analyzed using a 2-tailed Spearman's correction analysis. The other data are presented as the means \pm standard error of the mean (SEM) and differences between groups were analyzed using a Student's t-test or ANOVA (with Dunnett's post hoc test). A value of $\mathrm{P}<0.05$ was considered to indicate a statistically significant difference.

\section{Results}

Rapamycin sensitizes the ZR-75-1 and MCF-7 cells to tamoxifen in vitro. To examine the effects of the combination of tamoxifen and rapamycin on cell viability, the MCF-7 and ZR-75-1 cells were treated with tamoxifen $(0-24 \mu \mathrm{M})$ and/or rapamycin $(40 \mathrm{nM})$ and examined by CCK- 8 assay (Fig. 1C and D). As shown in Fig. 1E and F, the inhibitory rates observed with the combination treatment with rapamycin plus tamoxifen reached $83 \%$ compared to those observed with treatment with tamoxifen alone (50\%) in the ZR-75-1 cells. Likewise, treatment with rapamycin in combination with tamoxifen suppressed cell growth by $79 \%$ compared to treatment with tamoxifen alone (55\%) in the MCF-7 cells. When the growth inhibition rates reached $50 \%$, the combination indices (CI) achieved were 0.699 and 0.745 in ZR-75-1 and
MCF-7 cells, respectively, suggesting that rapamycin functions synergistically with tamoxifen to inhibit the growth of $\mathrm{ER}^{+}$ breast cancer cells (Table I).

Rapamycin enhances the tamoxifen-induced apoptosis of ZR-75-1 and MCF-7 cells. Treatment with rapamycin plus tamoxifen led to a $40 \%$ induction of cell apoptosis compared to treatment with tamoxifen alone (19\%) in the ZR-75-1 cells (Fig. 2A and C). The apoptotic rate observed with treatment with tamoxifen in combination with rapamycin was $45 \%$ compared to treatment with tamoxifen alone (22\%) in the MCF-7 cells (Fig. 2B and D). These results demonstrate that rapamycin is capable of functioning synergistically with tamoxifen to enhance the tamoxifen-induced apoptosis of the ZR-75-1 and MCF-7 cells.

Effects of rapamycin and tamoxifen on the growth of $E R^{+}$ breast cancer in vivo. As shown in Fig. 3A and B, compared to the control group, the combination treatment group (rapamycin + tamoxifen) exhibited a significant inhibition of tumor growth by $79.1 \%$ at 4 weeks. However, the groups which received rapamycin or tamoxifen alone exhibited a suppression of tumor growth of only 29.9 and $58.8 \%$, respectively, compared with the control group. Furthermore, the tumor weight of the combination treatment group was the lightest of the 4 groups (Fig. 3C). These results indicated that the combination of rapamycin or tamoxifen significantly and synergistically inhibited tumor growth in vivo.

IHC staining of $p 73$ and ER in human breast cancer tissues. As rapamycin is an inducer of p73, we hypothesized that this synergistic effect may be mediated partly through the upregulation of ER expression following the induction of p73. To examine the association between p73 and ER $\alpha$, IHC staining was performed in 82 breast cancer tissues. As shown in Fig. 4A, p73 was mainly expressed in the cytoplasm and $\mathrm{ER} \alpha$ was mainly expressed in the nucleus. Representative images of p73 expression in breast cancer tissues expressing high and low levels of ER $\alpha$ are presented in Fig. 4B. Table II shows the analysis of the association of p73 expression and the clinicopathological characteristics of the breast cancer patients. Additionally, we also found that there was a positive correlation between the expression levels of p73 and ER $\alpha$ in the breast cancer specimens (two-tailed Spearman's correlation analysis, $r=0.723, \mathrm{P}<0.05$ ) (Fig. $4 \mathrm{C}$ ). On the whole, these data suggested that ER $\alpha$ expression positively correlated with p73 expression in breast cancer tissues.

p73 regulates ER $\alpha$ expression in MCF-7 and ZR-75-1 cells. To examine whether p73 regulates ER $\alpha$ expression in breast cancer, the MCF-7 and ZR-75-1 cells were transiently transfected with siRRNA and scramble siRNA. As shown in Fig. 5C and D, the expression of ER $\alpha$ in the MCF-7 cells was effectively downregulated by siRNA against p73 compared with the cells transfected with the scramble siRNA (CTRi) at both the protein and mRNA level. Moreover, a p73 overexpression plasmid was transfected into the MCF-7 cell lines and the effects of p73 on $\mathrm{ER} \alpha$ expression were investigated by RT-qPCR and western blot analysis. As shown in Fig. 5A and B, the expression of $\mathrm{ER} \alpha$ was upregulated in the MCF-7 cells transfected with the 
Table I. Multiple drug dose-effect calculations and the combination index generated using GraphPad Prism software.

\begin{tabular}{lcccccc}
\hline Cell line & RAPA $(\mu \mathrm{M})$ & TAM $(\mu \mathrm{M})$ & Growth inhibition $(\%)$ & CI & Effect & P-value \\
\hline ZR75-1 & 3 & 10.2 & 50 & 0.699 & Synergy & $<0.05$ \\
MCF-7 & 2.5 & 7.4 & 50 & 0.745 & Synergy & $<0.05$ \\
\hline
\end{tabular}

CI, combination indices.

A
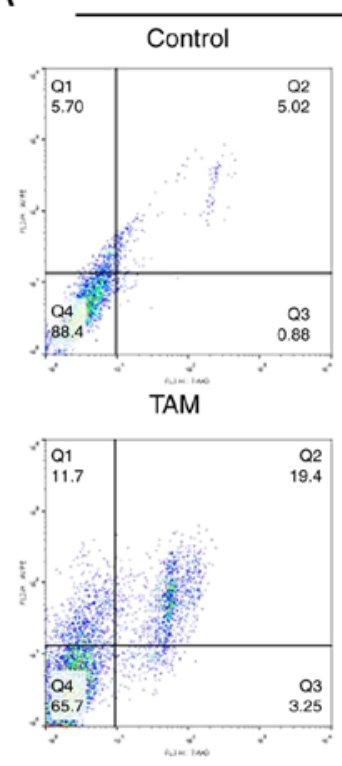

C

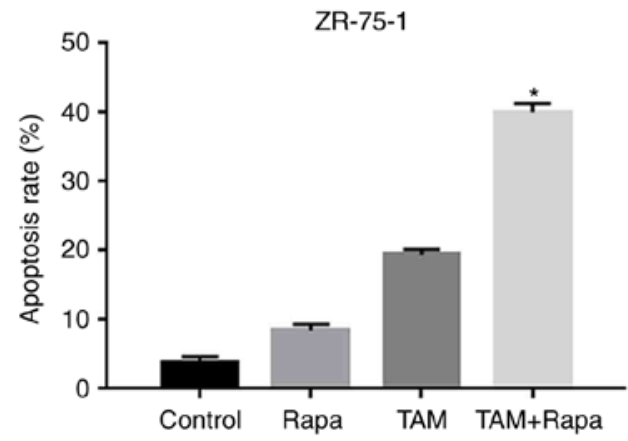

B

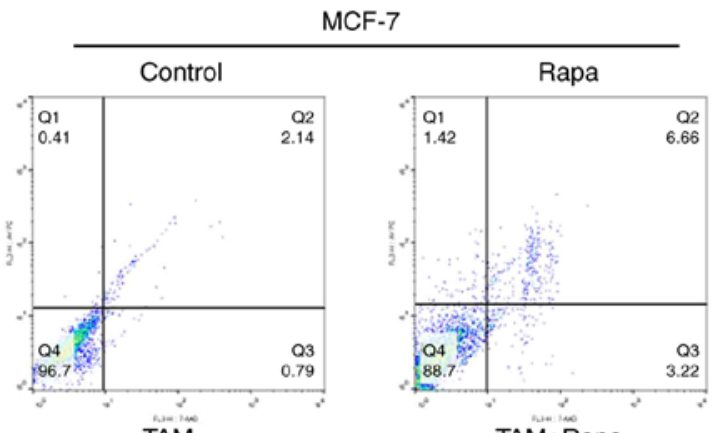

$\mathrm{TAM}+\mathrm{Rapa}$

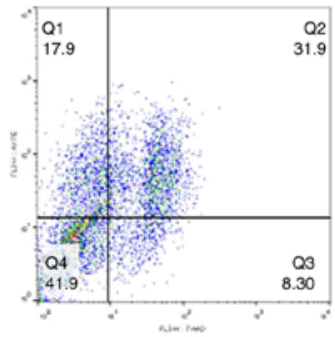

MCF-7

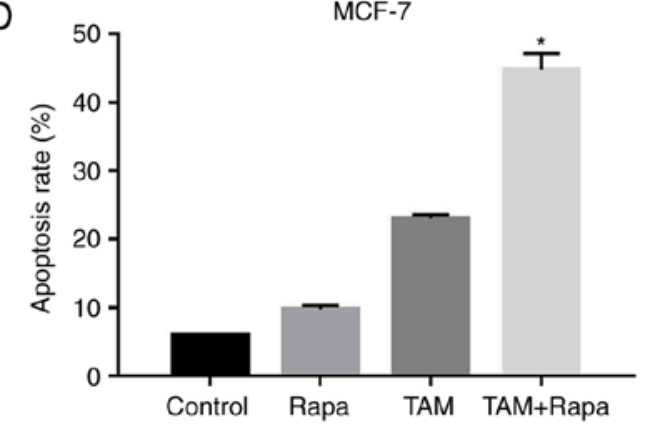

Figure 2. Rapamycin enhances the tamoxifen-induced apoptosis of ZR-75-1 and MCF-7 cells. (A and B) MCF-7 and ZR-75-1 cells were treated with tamoxifen $(9 \mu \mathrm{M})$ and/or rapamycin $(40 \mathrm{nM})$ for $48 \mathrm{~h}$. Following treatment, the cells were stained with PE/AnnexinV vs. 7-AAD to examine the apoptosis of the cells. (C and D) Histograms represent the quantification of apoptotic cells. The combination of the two drugs induced more significant apoptotic effects compared to the other groups. These data were calculated from 3 separate experiments and are presented as the means $\pm \mathrm{SEM}$. ${ }^{*} \mathrm{P}<0.05$ for the TAM $(9 \mu \mathrm{M})$ group vs. The TAM $(9 \mu \mathrm{M})+$ Rapa (40 nM) group. TAM, tamoxifen; Rapa, rapamycin.

p73 overexpression plasmid compared with that of the empty vector-transfected cells. Similar results were also observed in the ZR-75-1 cells (Fig. 5E-H). These data suggest that p73 positively regulates $\mathrm{ER} \alpha$ expression in $\mathrm{ER}^{+}$breast cancer cells.

p73 directlybinds to the ER a promoter region. To further investigate whether $\mathrm{p} 73$ regulates $\mathrm{ER} \alpha$ transcription, we hypothesized that $\mathrm{p} 73$ regulates the expression of $\mathrm{ER} \alpha$ by directly binding to ER $\alpha$ DNA. A shown by the schematic diagram in Fig. 6A, the luciferase reporter constructs contain the E-box in the promoter region of the ER $\alpha$ gene. Thus, the MCF-7 and ZR-75-1 cells were transfected with a luciferase reporter containing promoter of the ER $\alpha$ gene in order to determine whether p53 directly controls the transcription of the ER gene. The results revealed a 1.6- and 1.3-fold increase in luciferase activity in the MCF-7 and ZR-75-1 cells compared to the control vector-transfected cells, respectively (Fig. 6B and C). Furthermore, ChIP assays revealed that $\mathrm{p} 73$ binds to this E-box in the promoter region of ER $\alpha$ in the MCF-7 cells (Fig. 6D). GAPDH, which represented a negative control, was not bound by $\mathrm{p} 73$. These data indicate that p73 directly regulates ER $\alpha$ expression by binding to the E-box elements in the promoter region of the ER $\alpha$ gene. 

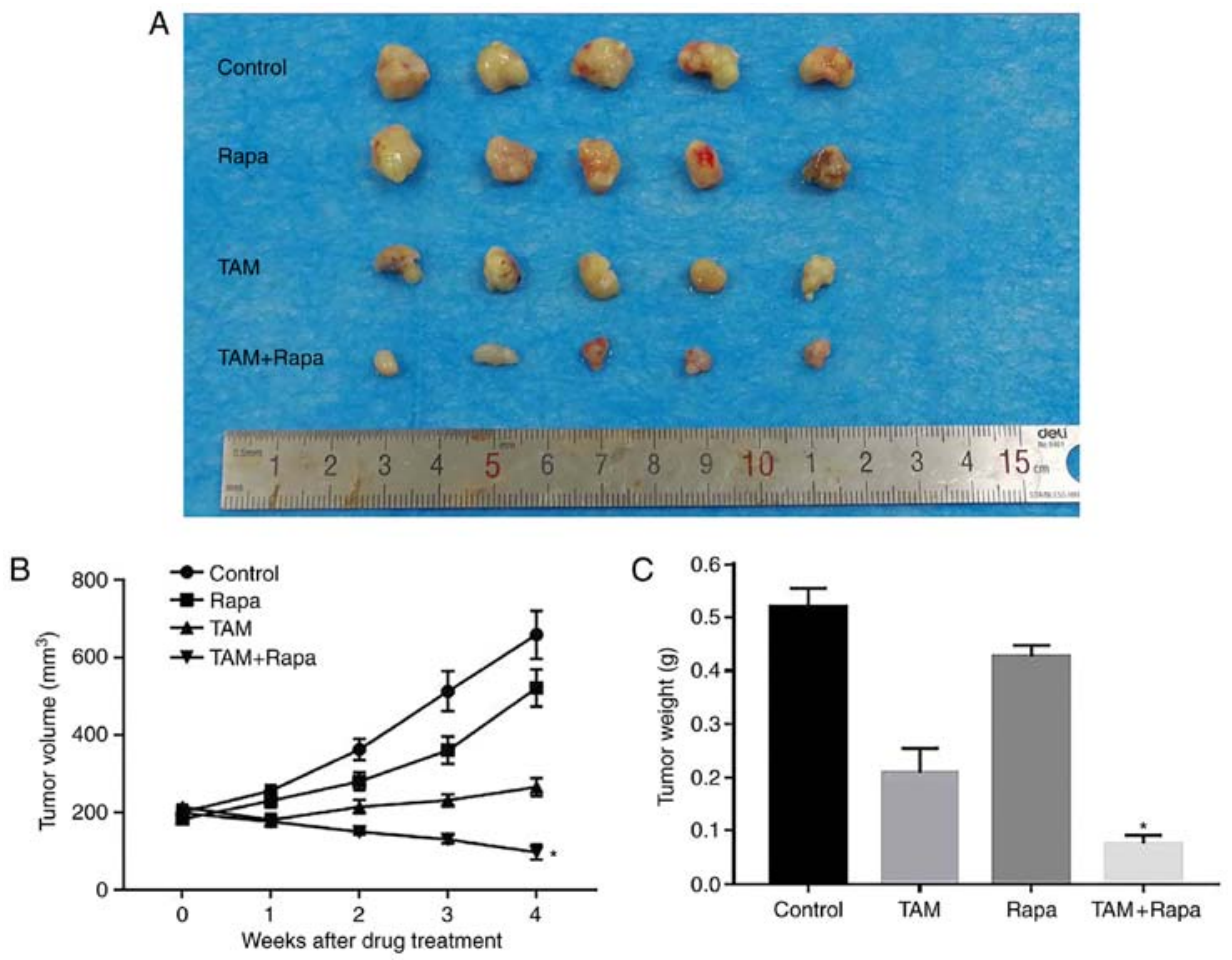

Figure 3. Effects of rapamycin and tamoxifen on the growth of ER+ breast cancer in vivo. (A) Images of typical tumors are shown. (B) Tumor growth curve. The mice treated with tamoxifen plus rapamycin formed smaller tumor volume compared to other groups. (C) Histograms represent the weight of tumors from the different groups. The tumor weight of the combination treatment group (TAM+Rapa) was the lightest of the 4 groups. Statistical analysis was performed using one-way ANOVA and the Student's t-test with the day 28 values only. " $\mathrm{P}<0.05$ compared with the TAM group. TAM, tamoxifen; Rapa, rapamycin.

A
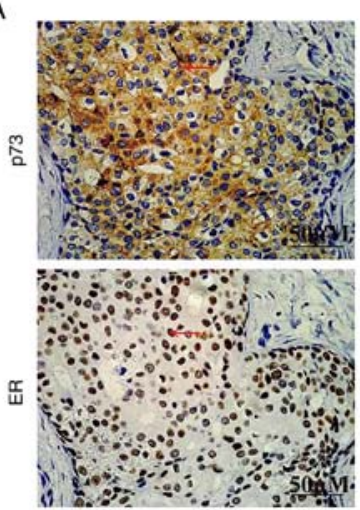

B
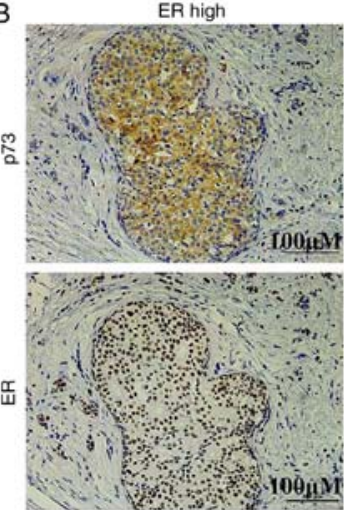

ER low
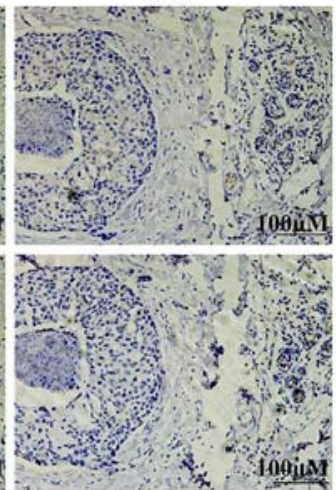

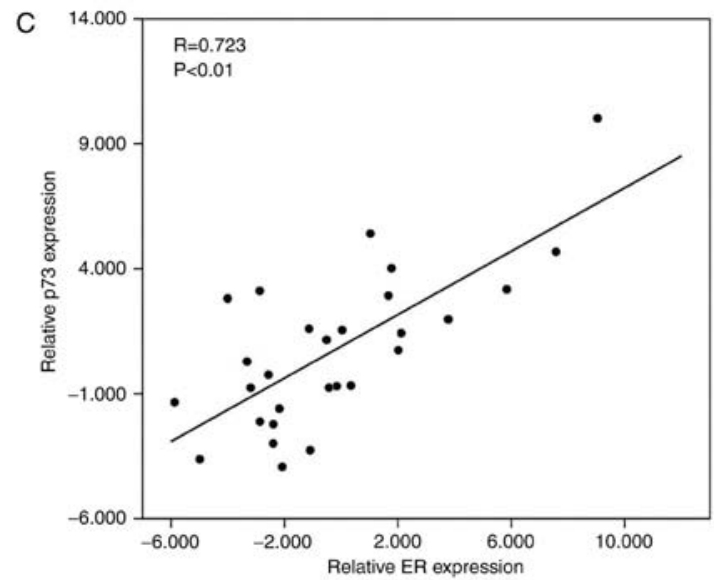

Figure 4. p73 expression is positively associated with ER $\alpha$ in human breast cancer tissues. (A) IHC analysis of p73 and ER $\alpha$ expression in breast cancer at x400 magnification. p73 was mainly expressed in the cytoplasm and ER $\alpha$ was mainly expressed in the nucleus. Scale bars, $50 \mu \mathrm{m}$. (B) IHC analysis of p73 and ER $\alpha$ expression in breast cancer at x200 magnification. Breast cancer tissues with a high expression of ER $\alpha$ expressed high levels of p73; breast cancer tissues with a low expression of ER $\alpha$ expressed low levels of p73. Scale bars, $50 \mu \mathrm{m}$. (C) A positive correlation was observed between the expression levels of p73 and $\mathrm{ER} \alpha$ in breast cancer specimens $(\mathrm{P}<0.05)$. ER, estrogen receptor. 
A
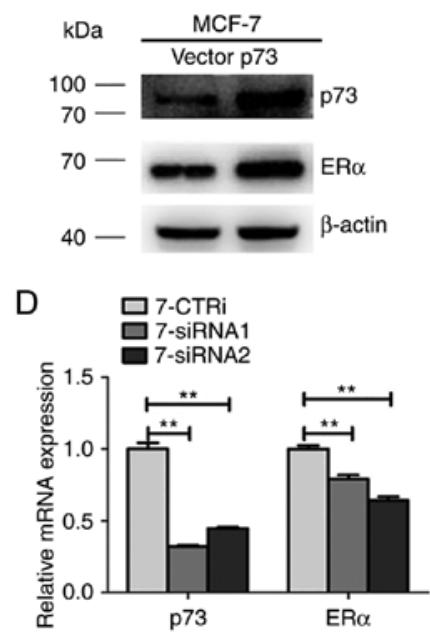

G

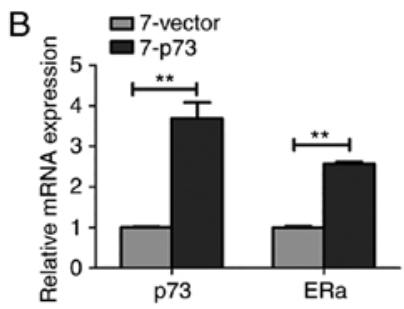

$\mathrm{E}$

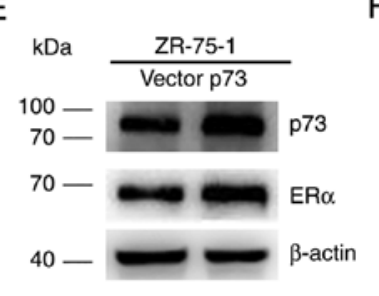

C

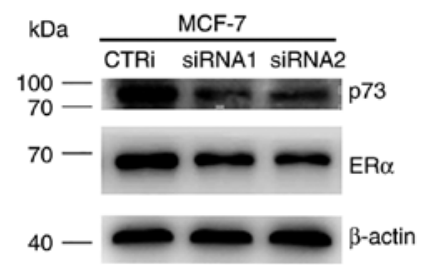

$\mathrm{F}$

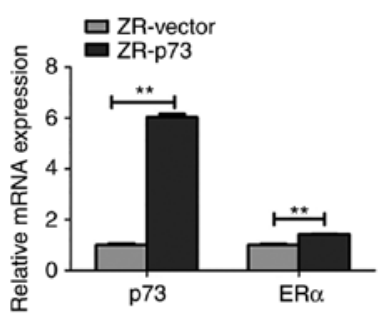

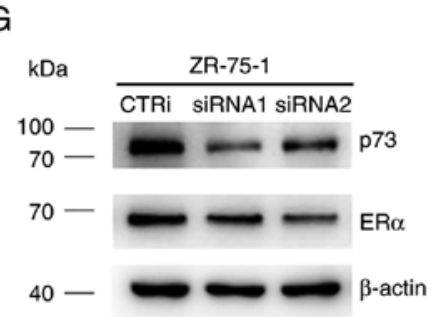

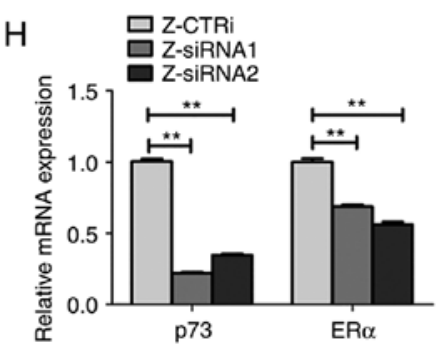

Figure 5. p73 regulates ER $\alpha$ expression in breast cancer cells. (A, B, E and F) MCF-7 and ZR-75-1 cells were transfected with a plasmid to overexpress p73 (p73) and the control (vector). ER $\alpha$ expression was significantly increased at both the protein (A and E) and mRNA level (B and F) following p73 overexpression. (C, D, G and H) MCF-7 and ZR-75-1 cells were transfected with siRNA to knockdown p73 (siRNA1, siRNA2) or control siRNA (CTRi). ER $\alpha$ expression was significantly decreased at both the protein (C and G) and mRNA level (D and H) following p73 knockdown. Western blot analysis and RT-qPCR were performed to detect the expression of $\mathrm{p} 73$ and $\mathrm{ER} \alpha$ at the protein and mRNA level. Results are representative of 3 independent experiments and are presented as the means $\pm \mathrm{SEM},{ }^{* *} \mathrm{P}<0.01$. ER, estrogen receptor.

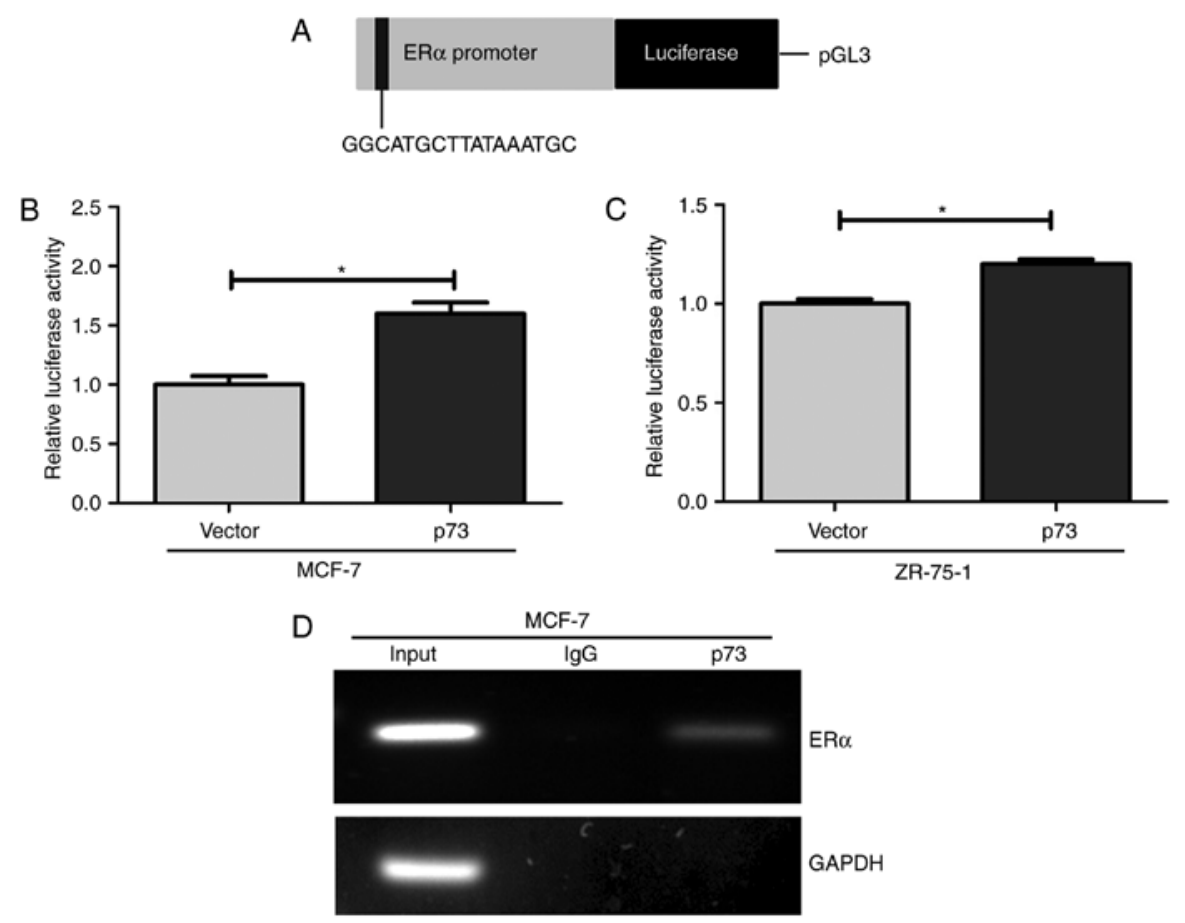

Figure 6. p73 regulates ER $\alpha$ expression by binding to the promoter region of the ER $\alpha$ gene in breast cancer cells. (A) Schematic diagram of the luciferase reporter constructs containing the E-box in promoter region of the ER $\alpha$ gene. (B and C) MCF-7 and ZR-75-1 cells transfected with the p73 overexpression plasmid or the control were transfected with the pGL3 control reporter or pGL3 reporter carrying the E-box in promotor region of the ER $\alpha$ gene. The increased fold in relative luciferase activity was a product of the luciferase activity induced by p73 overexpression divided by that induced by the control. Results are representative of 3 independent experiments and are presented as the means \pm SEM. ${ }^{*} \mathrm{P}<0.05$. (D) p73 directly binds to E-box in promoter region of the ER $\alpha$ gene. Lane 1, input DNA; lane 2, DNA from MCF-7 cells immunoprecipitated with normal mouse IgG; lane 3, DNA from MCF-7 cells immunoprecipitated with anti-p73 antibody. ER, estrogen receptor. 
Table II. Association of p73 with $\mathrm{ER} \alpha$ and clinicopathological characteristics of breast cancer patients.

$$
\text { p73 expression }
$$

\begin{tabular}{|c|c|c|c|c|}
\hline \multirow[b]{2}{*}{ Clinicopathological characteristics } & & & & \\
\hline & No. of cases & Low $(\%)$ & High (\%) & P-value \\
\hline Age, years & & & & 0.247 \\
\hline$<50$ & 35 & $26(74.3)$ & $9(25.7)$ & \\
\hline$\geq 50$ & 47 & $29(61.7)$ & $18(37.9)$ & \\
\hline Pathological grade & & & & 0.482 \\
\hline I-II & 43 & $27(62.8)$ & $16(37.2)$ & \\
\hline III & 39 & $28(71.8)$ & $11(28.2)$ & \\
\hline TNM stage & & & & 0.983 \\
\hline I-II & 76 & $51(67.1)$ & $25(32.9)$ & \\
\hline III & 6 & $4(66.7)$ & $2(33.3)$ & \\
\hline Tumor size (cm) & & & & 0.459 \\
\hline$\leq 2$ & 28 & 17 (60.7) & $11(39.3)$ & \\
\hline$>2$ & 54 & $38(70.4)$ & $16(29.6)$ & \\
\hline Lymph node metastasis & & & & 0.920 \\
\hline No & 51 & $34(66.7)$ & $17(33.3)$ & \\
\hline N1-N3 & 31 & $21(67.7)$ & $10(32.3)$ & \\
\hline ER & & & & 0.019 \\
\hline Negative & 46 & $36(78.3)$ & $10(21.7)$ & \\
\hline Positive & 36 & $19(52.8)$ & $17(47.2)$ & \\
\hline PR & & & & 0.945 \\
\hline Negative & 68 & $46(67.6)$ & $22(32.4)$ & \\
\hline Positive & 14 & $9(64.3)$ & $5(35.7)$ & \\
\hline Her2 & & & & 0.232 \\
\hline Negative & 33 & $25(75.8)$ & $8(24.2)$ & \\
\hline Positive & 49 & $30(61.2)$ & $19(38.8)$ & \\
\hline
\end{tabular}

ER, estrogen receptor; PR, progesterone receptor.

\section{Discussion}

In the present study, we found that the mTOR inhibitor, rapamycin, which has been approved by the FDA for the prevention of organ transplant rejection, enhances the sensitivity of $\mathrm{ER}^{+}$breast cancer cells to tamoxifen partly through the upregulation of ER expression following the induction of $\mathrm{p} 73$.

In patients with metastatic breast cancers, tamoxifen treatment would leads to disease regression in $\sim 30 \%$ of cases (30). Patients who receive tamoxifen treatment for 0 to 4 years obtain maximal benefits, with a reduced recurrence rate $51 \%$ and a reduced death rate by $28 \%$. The reduction in recurrence and mortality is sustained in year 5 and beyond $(30,31)$. In a recent study, the worldwide Adjuvant Tamoxifen: Longer Against Shorter (ATLAS) trial, indicated that 10 years of tamoxifen treatment reduced breast cancer recurrence and mortality more effectively than treatment for 5 years (32). This fully affirmed the efficacy of tamoxifen in the treatment for $\mathrm{ER}^{+}$ breast cancer, while its severe side-effects following long-term and high-dose treatment must still be seriously considered. In this study, we observed the synergistic effects of tamoxifen and rapamycin used in combination in $\mathrm{ER}^{+}$breast cancer cell lines. In addition, this synergistic effect of rapamycin and tamoxifen was confirmed using a nude mouse model in vivo. The dose of rapamycin $(40 \mathrm{nM})$ used in combination with tamoxifen was lower than that of metformin $(5 \mathrm{mM})$ and celecoxib $(30 \mu \mathrm{M})$ used in previous studies $(19,20)$. This indicates that rapamycin may be a more desirable drug for the prevention of breast cancers and the growth inhibition of existing tumors in women. To date, apart from breast cancer, the combination of rapamycin and CC-5013 (Revlimid) has been shown to improve patient outcome in multiple myeloma (33). Of note, in this study, the concentration of tamoxifen required for growth inhibition was substantially reduced when rapamycin was combined with tamoxifen.

The mTOR pathway plays a crucial role in multiple cellular processes and is the most frequently activated signaling pathway, which promotes tumor growth and progression (34). Gene alterations in the mTOR pathway are frequently observed in $\mathrm{ER}^{+}$breast cancer. These include insulin-like growth factor 1 receptor (IGF-1R), phosphatidylinositide 3-kinase (PI3K) and human epidermal growth factor receptor 2 (HER2) gene amplifications (35-37) or phosphatase and tensin homolog (PTEN) gene function loss (38). Correspondingly, the loss of PTEN 
expression is associated with low ER $\alpha$ levels and high PI3K activity, which may result in a poor response to tamoxifen treatment $(39,40)$. Hence, the hyperactivation of the mTOR pathway may lead to the downregulation of ER $\alpha$ expression and may promote hormone-independent cell growth. mTOR inhibitors (e.g., rapamycin) may reverse this process by increasing ER $\alpha$ levels, thereby restoring hormone dependence and sensitivity to endocrine therapy (41).

A crosstalk exists between the mTOR pathway, and ER $\alpha$ and p53-family members. p53 has been reported to regulate ER $\alpha$ expression through transcriptional control by binding to the ER $\alpha$ promoter (42). p73 is structurally and functionally related to p53; however, to date, at least to the best of our knowledge, there are no studies available on the interaction between p73 and ER $\alpha$. Additionally, rapamycin can selectively increase p73 occupancy at its binding sites and modulate its activity and function (43). As both ER and p73 are involved in the mTOR pathway, we hypothesized that the activation of $\mathrm{p} 73$ may regulate ER $\alpha$ expression. In this stuyd, IHC and tissue microarray analysis were applied to confirm the association between p73 and ER $\alpha$. Moreover, the upregulation of p73 resulted in an increased ER $\alpha$ mRNA and protein expression, whereas the knockdown of p73 decreased the levels of ER $\alpha$ protein and transcript in the $\mathrm{ER}^{+}$breast cancer cells. These data suggest that the expression of p73 and ER $\alpha$ is linked in $\mathrm{ER}^{+}$breast cancer, which would be expected to account for the synergistic effects of rapamycin plus tamoxifen.

The combination of tamoxifen and rapamycin, though, has not been previously investigated in clinical trials, at least to the best of our knowledge. However, was previously reported that the mTORC1 inhibitor, everolimus, plus tamoxifen increased the 6-month clinical benefit rate by $61 \%$ compared to $42 \%$ with tamoxifen alone and reduced the risk of death by $55 \%$ in women with metastatic breast cancer. Moreover, the progression time appeared to be more prolonged with the combination vs. tamoxifen alone (8.6 months vs. 4.5 months, hazard ratio 0.54) (44).

In conclusion, in the present study, we revealed a novel mechanism in that p73 transcriptionally regulates ER $\alpha$ expression by directly binding in its promoter region. In addition, combination therapy with an mTOR inhibitor and tamoxifen, leading to the activation of p73 may provide new insight and may aid in the development of novel strategies for the treatment of patients with $\mathrm{ER}^{+}$breast cancers.

\section{Acknowledgements}

Not applicable.

\section{Funding}

This study was supported by the Natural Science Foundation of China (grant nos. 81572595, 81602336 and 81202077) and the Key Medical Subjects of Jiangsu Province (grant no. H201110 to QD).

\section{Availability of data and materials}

The datasets analyzed during the current study are available from the corresponding author on reasonable request.

\section{Authors' contributions}

QD, JW, JFW and LZ contributed to the design of this study. XXL, LS and JW contributed to the experimental work. JYQ, TSX and WBZ contributed to the data collection and analysis. $\mathrm{XS}, \mathrm{XJZ}$ contributed to the interpretation of the data and the drafting of the manuscript. All authors read and approved the manuscript and agree to be accountable for all aspects of the research in ensuring that the accuracy or integrity of any part of the work are appropriately investigated and resolved.

\section{Ethics approval and consent to participate}

The collection and use of the samples was reviewed and approved by the Institutional Ethics Committee of the First Affiliated Hospital of Nanjing Medical University and informed consent was obtained from all patients prior to sample collection. The use of animals in this study was approved by the Institutional Animal Care and Use Committee for Animal Use (the Animal Ethics Committee of Nanjing Medical University).

\section{Patient consent for publication}

Not applicable.

\section{Competing interests}

The authors declare that they have no competing interests.

\section{References}

1. Cancer Genome Atlas Network: Comprehensive molecular portraits of human breast tumors. Nature 490: 61-70, 2012.

2. Sørlie T, Perou CM, Tibshirani R, Aas T, Geisler S, Johnsen H, Hastie T, Eisen MB, van de Rijn M, Jeffrey SS, et al: Gene expression patterns of breast carcinomas distinguish tumor subclasses with clinical implications. Proc Natl Acad Sci USA 98: 10869-10874, 2001.

3. Creighton CJ: The molecular profile of luminal B breast cancer. Biologics 6: 289-297, 2012.

4. Katzenellenbogen BS and Katzenellenbogen JA: Estrogen receptor transcription and transactivation: Estrogen receptor alpha and estrogen receptor beta: Regulation by selective estrogen receptor modulators and importance in breast cancer. Breast Cancer Res 2: 335-344, 2000.

5. Burns KA and Korach KS: Estrogen receptors and human disease: An update. Arch Toxicol 86: 1491-1504, 2012.

6. Higa GM and Fell RG: Sex hormone receptor repertoire in breast cancer. Int J Breast Cancer 2013: 284036, 2013.

7. Yager JD and Davidson NE: Estrogen carcinogenesis in breast cancer. N Engl J Med 354: 270-282, 2006.

8. Shanle EK and $\mathrm{Xu} \mathrm{W:} \mathrm{Selectively} \mathrm{targeting} \mathrm{estrogen} \mathrm{receptors}$ for cancer treatment. Adv Drug Deliver Rev 62: 1265-1276, 2010.

9. Britton DJ, Hutcheson IR, Knowlden JM, Barrow D, Giles M, McClelland RA, Gee JMW and Nicholson RI: Bidirectional cross talk between ERalpha and EGFR signalling pathways regulates tamoxifen-resistant growth. Breast Cancer Res Treat 96: 131-146, 2006.

10. Jeselsohn R, Buchwalter G, De Angelis C, Brown M and Schiff R: ESR 1 mutations-a mechanism for acquired endocrine resistance in breast cancer. Nat Rev Clin Oncol 12: 573-583, 2015.

11. Morandi A, Martin L, Gao Q, Pancholi S, Mackay A, Robertson D, Zvelebil M, Dowsett M, Plaza-Menacho I and Isacke CM: GDNF-RET signaling in ER-positive breast cancers is a key determinant of response and resistance to aromatase inhibitors. Cancer Res 73: 3783-3795, 2013.

12. Wang P, Bahreini A, Gyanchandani R, Lucas PC, Hartmaier RJ, Watters RJ, Jonnalagadda AR, Trejo Bittar HE, Berg A, Hamilton RL, et al: Sensitive detection of mono- and polyclonal ESR 1 mutations in primary tumors, metastatic lesions and cell free DNA of breast cancer patients. Clin Cancer Res 22: 1130-1137, 2016. 
13. Ali S and Coombes RC: Endocrine-responsive breast cancer and strategies for combating resistance. Nat Rev Cancer 2: 101-112, 2002.

14. Stathopoulos GP and Trafalis D: High-dose tamoxifen in breast cancer bone metastasis. J BUON 18: 532-534, 2013.

15. Hendrick A and Subramanian VP: Tamoxifen and thromboembolism. JAMA 243: 514-515, 1980.

16. Musgrove EA and Sutherland L: Biological determinants of endocrine resistance in breast cancer. Nat Rev Cancer 9: 631-643, 2009.

17. Lorizio W, Wu AH, Beattie MS, Rugo H, Tchu S, Kerlikowske K and Ziv E: Clinical and biomarker predictors of side effects from tamoxifen. Breast Cancer Res Treat 132: 1107-1118, 2012.

18. Castrellon AB: Novel strategies to improve the endocrine therapy of breast cancer. Oncol Rev 11: 323, 2017.

19. Ma J, Guo Y, Chen S, Zhong C, Xue Y, Zhang Y, Lai X, Wei Y, Yu S, Zhang J, et al: Metformin enhances tamoxifen-mediated tumor growth inhibition in ER-positive breast carcinoma. BMC Cancer 14: 172, 2014.

20. Kumar BN, Rajput S, Dey KK, Parekh A, Das S, Mazumdar A and Mandal M: Celecoxib alleviates tamoxifen-instigated angiogenic effects by ROS-dependent VEGF/VEGFR2 autocrine signaling. BMC Cancer 13: 273, 2013.

21. Hare SH and Harvey AJ: mTOR function and therapeutic targeting in breast cancer. Am J Cancer Res 7: 383-404, 2017.

22. Wong SW, Tiong KH, Kong WY, Yue YC, Chua CH, Lim JY, Lee CY, Quah SI, Fow C, Chung C, et al: Rapamycin synergizes cisplatin sensitivity in basal-like breast cancer cells through up-regulation of p73. Breast Cancer Res Treat 128: 301-313, 2011.

23. Martin L, Pancholi S, Farmer I, Guest S, Ribas R, Weigel MT, Thornhill AM, Ghazoui Z, A'Hern R, Evans DB, et al: Effectiveness and molecular interactions of the clinically active mTORC1 inhibitor everolimus in combination with tamoxifen or letrozole in vitro and in vivo. Breast Cancer Res 14: R132, 2012.

24. Chou T and Talalay P: Quantitative analysis of dose-effect relationships: The combined effects of multiple drugs or enzyme inhibitors. Adv Enzyme Regul 22: 27-55, 1984.

25. Schindlbeck C, Jeschke U, Schulze S, Karsten U, Janni W, Rack B, Krajewski S, Sommer H and Friese K: Prognostic impact of Thomsen-Friedenreich tumor antigen and disseminated tumor cells in the bone marrow of breast cancer patients. Breast Cancer Res Treat 101: 17-25, 2007.

26. Lou P, Li C, Shi L, Xia TS, Zhou W, Wu J, Zhou X, Li X, Wang Y, Wei JF, et al: RNPC1 enhances progesterone receptor functions by regulating its mRNA stability in breast cancer. Oncotarget 8 : 16387-16400, 2017.

27. Shi L, Xia T, Wei X, Zhou W, Xue J, Cheng L, Lou P, Li C, Wang Y, Wei JF, et al: Estrogen receptor (ER) was regulated by RNPC1 stabilizing mRNA in ER positive breast cancer. Oncotarget 6: 12264-12278, 2015.

28. Livak KJ and Schmittgen TD: Analysis of relative gene expression data using real-time quantitative PCR and the $2^{-\Delta \Delta C_{\mathrm{T}}}$ method. Methods 25: 402-408, 2001.

29. Li XX, Shi L, Zhou XJ, Wu J, Xia TS, Zhou WB, Sun X, Zhu L, Wei JF and Ding Q: The role of c-Myc-RBM38 loop in the growth suppression in breast cancer. J Exp Clin Cancer Res 36: 49, 2017.

30. Tamoxifen for early breast cancer: An overview of the randomised trials. Early breast cancer trialists' collaborative group. Lancet 351: 1451-1467, 1998.

31. Osborne CK: Tamoxifen in the treatment of breast cancer. N Engl J Med 339: 1609-1618, 1998.
32. Davies C, Pan H, Godwin J, Gray R, Arriagada R, Raina V, Abraham M, Medeiros Alencar VH, Badran A, Bonfill X, et al: Long-term effects of continuing adjuvant tamoxifen to 10 years versus stopping at 5 years after diagnosis of oestrogen receptor-positive breast cancer: ATLAS, a randomised trial. Lancet 381: 805-816, 2013.

33. Raje N, Kumar S, Hideshima T, Ishitsuka K, Chauhan D, Mitsiades C,Podar K, Le Gouill S, Richardson P, Munshi NC, et al: Combination of the mTOR inhibitor rapamycin and CC-5013 has synergistic activity in multiple myeloma. Blood 104: 4188-4193, 2004.

34. Markman B, Dienstmann R and Tabernero J: Targeting the $\mathrm{PI} 3 \mathrm{~K} / \mathrm{Akt} / \mathrm{mTOR}$ pathway-beyond rapalogs. Oncotarget 1: 530-543, 2010

35. Ellis MJ,Tao Y, Young O, White S,Proia AD, Murray J, Renshaw L, Faratian D, Thomas J, Dowsett M, et al: Estrogen-independent proliferation is present in estrogen-receptor HER2-positive primary breast cancer after neoadjuvant letrozole. J Clin Oncol 24: 3019-3025, 2006

36. Law JH, Habibi G, Hu K, Masoudi H, Wang MY, Stratford AL, Park E, Gee JM, Finlay P, Jones HE, et al: Phosphorylated insulin-like growth factor-i/insulin receptor is present in all breast cancer subtypes and is related to poor survival. Cancer Res 68: 10238-10246, 2008.

37. Creighton CJ, Fu X, Hennessy BT, Casa AJ, Zhang Y, Gonzalez-Angulo AM, Lluch A, Gray JW, Brown PH, Hilsenbeck SG, et al: Proteomic and transcriptomic profiling reveals a link between the PI3K pathway and lower estrogen-receptor (ER) levels and activity in ER+ breast cancer. Breast Cancer Res 12: R40, 2010.

38. Saal LH, Johansson P, Holm K, Gruvberger-Saal SK, She QB, Maurer M, Koujak S, Ferrando AA, Malmström P, Memeo L, et al: Poor prognosis in carcinoma is associated with a gene expression signature of aberrant PTEN tumor suppressor pathway activity. Proc Natl Acad Sci USA 104: 7564-7569, 2007.

39. Gonzalez-Angulo AM, Ferrer-Lozano J, Stemke-Hale K, Sahin A, Liu S, Barrera JA, Burgues O, Lluch AM, Chen H, Hortobagyi GN, et al: PI3K pathway mutations and PTEN levels in primary and metastatic breast cancer. Mol Cancer Ther 10: 1093-1101, 2011.

40. Pérez-Tenorio G, Alkhori L, Olsson B, Waltersson MA, Nordenskjöld B, Rutqvist LE, Skoog L and Stål O: PIK3CA mutations and PTEN loss correlate with similar prognostic factors and are not mutually exclusive in breast cancer. Clin Cancer Res 13: 3577-3584, 2007.

41. Ciruelos Gil EM: Targeting the PI3K/AKT/mTOR pathway in estrogen receptor-positive breast cancer. Cancer Treat Rev 40: 862-871, 2014.

42. Shirley SH, Rundhaug JE, Tian J, Cullinan-Ammann N, Lambertz I, Conti CJ and Fuchs-Young R: Transcriptional regulation of estrogen receptor-alpha by p53 in human breast cancer cells. Cancer Res 69: 3405-3414, 2009.

43. Rosenbluth JM, Mays DJ, Jiang A, Shyr Y and Pietenpol JA: Differential regulation of the $\mathrm{p} 73$ cistrome by mammalian target of rapamycin reveals transcriptional programs of mesenchymal differentiation and tumorigenesis. Proc Natl Acad Sci USA 108: 2076-2081, 2011

44. Bachelot T, Bourgier C, Cropet C, Ray-Coquard I, Ferrero J, Freyer G, Abadie-Lacourtoisie S, Eymard J, Debled M, Spaëth D, et al: Randomized phase II trial of everolimus in combination with tamoxifen in patients with hormone receptor-positive, human epidermal growth factor receptor 2-negative metastatic breast cancer with prior exposure to aromatase inhibitors: A GINECO study. J Clin Oncol 30: 2718-2724, 2012. 